\title{
MARCO ANTONIO MONTES DE OCA: ESE INMENSO MAR POETICO
}

\author{
POR \\ MIGUEL ANGEL FLORES \\ Universidad Autónoma Metropolitana-Azcapotzalco
}

En el presente año (1988), Marco Antonio Montes de Oca (1932) ha dado a conocer la tercera recopilación de sus poemas con el título de uno de sus libros originales: Pedir el fuego'. Se trata de un verdadero acontecimiento literario, pues en un sólo volumen se recoge una producción que abarca 34 años de quehacer poético. Montes de Oca es uno de nuestros poetas más singulares e importantes. Sin embargo, la recopilación de sus obras completas no ha merecido de la crítica la atención que merece.

Cabe recordar que la poesía de Montes de Oca ha sido siempre blanco de ataques e incomprensión, por su mismo carácter peculiar dentro del ámbito de la poesía mexicana. Curiosamente, se le han reprochado los rasgos que constituyen sus virtudes: desbordamiento, metáforas inesperadas, excesos, desmesura, caídas de gusto. Al referirnos a virtudes, queremos decir que con los rasgos anteriores los malos poetas han hecho retórica, en el mejor de los casos, mientras que Montes de Oca ha escrito verdadera poesía, empleando un lenguaje deslumbrante con el que ha tejido metáforas que difícilmente encuentran parangón en la lírica mexicana.

Octavio Paz saludó con entusiasmo el primer libro de Montes de $\mathrm{Oca}^{2}$. Menciona en el cuerpo de su nota, precisamente, que algunos críticos hayan reprochado al poeta "su riqueza de imágenes". Paz considera que éste es un reparo demasiado absurdo, como absurdo sería criticar "la esbeltez del chopo ola blancura

\footnotetext{
${ }^{1}$ Marco Antonio Montes de Oca. Pedir el fuego (Poesía: 1935-1987) (México: Joaquín Mortiz; Secretaría de Educación Pública, 1987: Col. Las đos orillas, serie mayor). Marco Antonio Montes de Oca ha hecho dos recopilaciones anteriores de su poesía: Poesía reunida (1953-1971) (México: Fondo de Cultura Económica, Letras mexicanas, 1971) y Comparencias (Barcelona: Seix-Barral, 1981).

${ }^{2}$ Marco Antonio Montes de Oca. Delante de la luz cantan los pájaros (México: Fondo de Cultura Económica. Letras mexicanas, 50, 1959).
} 
de la nieve”. Explosión verbal, eso es para Paz esta poesía. No -dice Paz-, la poesía no es excesiva, y termina confesando su deslumbramiento ante imágenes que transforman las palabras para hacerlas decir otra cosa. Antes, Paz había mencionado que la poesía mexicana, en el año en que aparece el primer libro de Montes de Oca, sufria de anemia parnasiana.

Otro gran poeta que se distinguió por su actividad crítica, Alí Chumacero, ha sido también de los pocos que se han ocupado de Montes de Oca. Alí, en su oportunidad comentó también el primer libro de Montes de Oca y caracterizó así su poesía:

Vigor y desmesura, plasticidad y violencia, impudor y crueldad, desbordado todo en el escándalo de la imagen, defienden estos imperfectos poemas que surgen de golpe 'como un árbol en mitad del mar'. Desbocado, diríamos; disparado, irrumpiente; enemigo del reposo, ajeno a la meditación, Montes de Oca se enfrenta a la poesía con la inexperiencia insobornable de la juventud. Acaso se equivoque, pero en las astillas que desprende perdura el afán de soportar el peso de la belleza que todo artista se compromete a descubrir'.

Al concluir su nota, Chumacero señala que estos poemas seguramente causarán extrañeza en los lectores que no estén acostumbrados a un tipo de poesía que exige lecturas reincidentes para que pueda ser interiorizado ese cúmulo de imágenes que brotan de un misterioso fluir. Para Alí, la pluma del joven poeta es libre, no la domeña el cansancio, pues el manantial del que surgen las metáforas parece inagotable, ni la reflexión. El poeta da curso a un proceso en el que se alían las palabras aparentemente sin mayor preocupación formal. Lo que importa es traducir la experiencia del mundo en imágenes, hacer un festín de metáforas que no alcance a saciar a ningún lector. Al terminar su reseña, Chumacero comenta que a partir de su primer libro, las extraordinarias dotes líricas de Montes de Oca habrían de ponerse a prueba. Afortunadamente para la pocsía mexicana, esas dotes

\footnotetext{
${ }^{3}$ Octavio Paz. Puertas al campo (México: Universidad Nacional Autónoma de México. Col. Poemas y ensayos, 1967). Artículo recogido en Octavio Paz. Generaciones y semblanzas: escritores y letras de México. Vol II de México en la obra de Octavio Paz, Edición de Octavio Paz y Luis Mario Schneider (México: Fondo de Cultura Económica, 1987).

- Subrayado de Octavio Paz (1ra, p.) (otra cosa)

${ }^{4}$ Alí Chumacero, "Marco Antonio Montes de Oca, enemigo del reposo o el canto solitario del poeta". México en la Cultura, núm. 555, 1 de noviembre de 1959. Recogido en Alí Chumacero. Los momentos críticos. Selección, prólogo y bibliografía de Miguel Angel Flores (México: Fondo de Cultura Económica. Col. Letras mexicanas, 1987).
} 
líricas han dado árboles cargados de frutos poéticos y han resistido más de tres décadas de incesante creación, que, como toda obra humana, presenta irregularidades, pero, vista en su conjunto, es una de las obras más espléndidas de la poesía mexicana de la segunda mitad de nuestro siglo.

Ante ese vasto conjunto poético que es Pedir el fuego, resulta interesante transcribir la poética de Montes de Oca, expresada más con un lenguaje metafórico que conceptual. Esos renglones que escribió para un ensayo autobiográfico nos hablan de un proceso creativo. Es, en cierta forma, la mirada retrospectiva de un autor que, al momento de escribir su autobiografía, ha publicado ya nueve libros de poesía. La autobiografía a la que hacemos referencia, está redactada con el mismo lenguaje con el que Montes de Oca ha construido sus poemas.

Nos podemos imaginar a éste como un creador que absorbe, en la sistole, palabras indiscriminadamente, y en su diástole expulsa metáforas insólitas.

Comenta Montes de Oca que en su juventud, mientras a los demás les atraía Juan Ramón Jiménez y Paul Valéry, él prefería a Bécquer. Lo que más admiraba en él era "el gran voltaje lírico desatado en sus rimas". De Juan Ramón le disgustaba su narcisimo; de Valéry, las pretenciosas arquitecturas. "La poesía representaba para mi -escribe Montes de Oca— algo más que una lección de filosofía aderezada con exlamaciones líricas. La pocsía es aditivo esencial del orden viviente; elemento añadido al ser, es cierto, pero que, una vez asimilado, aumenta su misma esencia”. Luego pasa a referirse a un ensayo de Ramón Gaya en el que éste escribe que Mozart, en los momentos de gran crisis personal, componía música del mayor optimismo. Esta idea expresada por Gaya tuvo gran efecto en Montes de oca, pues le hizo detestar la poesía confesional de quienes escriben para librarse de un peso interior, "sin que les preocupe el buceo aéreo de quienes buscan su rostro en el sueño y regresan con la presea del amor agitándose en la mano como un eterno ramo en llamas. De todo aquello que la literatura confesional olvida se compone el universo".

Para Montes de Oca, una de sus experiencias formativas más importantes durante su primera juventud fue su militancia en el "poeticismo", el movimiento literario más malogrado de la poesía mexicana. El poeta considera que, a pesar de que fue un acto fallido, "no deja de ser interesante por el esfuerzo teórico que sus fundadores aportaron". El problema del poeticismo, según Montes de Oca, consistia en que "mecanizaba la poesía proscribiendo la inspiración, ese recurso

\footnotetext{
${ }^{5}$ Marco Antonio Montes de Oca. Marco Antonio Montes de Oca (México: Empresas Editoriales. Col. Nuevos escritores mexicanos del siglo XX presentados por sí mismos, 1987). Esta autobiografía figura al frente de Poesía reunida, op. cit. Todas las citas están tomadas de este libro.
} 
que constituye nuestra única manera congénita de volar". En otra parte, el autor de Pedir el fuego, dice: "De cuantos principios sostenía el poeticismo, falsos en su mayoría, uno de ellos, el de la claridad, todavía me parece irrenunciable. El poema es algo que requiere ser entendido. El misterio mismo precisa de una semántica".

Al lector desprevenido le podría parecer que los poemas de Montes de Oca no se sujetan a ningún orden, que son caóticos, acaso porque no quiere esforzarse en desentrañar los postulados de esa semántica que menciona el mismo Montes de Oca. En algún lugar ha dicho el poeta: soy todo lo que miro. El poeta es sólo el sujeto que, a través del lenguaje, se apodera de cuanto lo rodea para incorporarlo a su ser mediante la metáfora, construyendo así otra realidad que se sujeta a leyes que instauran su propia lógica: la lógica de la imaginación; por ello Montes de Ocá dice: "Los objetos poseen una cara real y otra fantástica; son monedas con un anverso que podemos tocar y con un reverso que debemos imaginar". Imaginar ese anverso pone en movimiento al lenguaje, generando imágenes que no conocen límite, pues el impulso de su vuelo describe trayectorias audaces. En una tradición poética, en la que el tono menor está presente - algo que irrita a Montes de Oca, y reprocha a Pedro Henríquez Ureña que se haya referido a este rasgo de la poesía como la nota dominante en la lírica mexicana-, el poeta traza poemas de largo alcance, de gran ambición, al que se van sumando toda su experiencia del momento; poemas que buscan asediar un objeto o una situación desde todos sus ángulos y planos. Por ello, la yuxtaposición, el simultaneísmo, es el efecto mås buscado, pues la sensación de totalidad conforma la aspiración del poeta. En el largo desarrollo de un tema no es éste el que importa, sino los varios puntos de vista que de él puede obtener el poeta; pero esa diversidad, al estar dicha con un medio que tiene como exigencia la sucesión, cuando lo que importa al autor es captar y transmitir un momento determinado, en la pluralidad de un punto de vista, se corre el riesgo de la confusión o de un hermetismo que tal vez no pueda jamás revelar sus significados. Lo que más preocupa, por ese motivo, a Montes de Oca, es la claridad. Dice:

El poema de larga extensión, cuajado de presencias que se mutilan unas a otras en su penosa disputa por obtener un mínimo del espacio comunizado que las envuelve, no es fruto que rinda su almendra secreta al primer asalto. En este caso, la función del lector consiste en unificar impresiones parciales y en deducir de ellas su significación global. Tal función es imposible cuando, por ineficacia expresiva, por arbitraricdad o gratuito apego al hermetismo, el autor tira al río las llaves del poema. 
Aparentemente hay arbitrariedad en esta poesia, pero las apariencias, una vez más, engañan. Lo que hay aquí son muchas visiones yuxtapuestas que componen una materia imaginativa difícil de apreciar en una primera lectura. Pero al poeta no le ha bastado proponer una primera lectura única. En cada oportunidad ha reescrito los poemas, les ha dado un ordenamiento distinto, siempre con el propósito de que las metáforas expresen con más nitidez el rostro oculto de la realidad poética, y también porque, para Montes de Oca, el proceso de la creación es un movimiento incesante, que provoca cambios en el punto de observación de la realidad y genera asociaciones que enriquecen la primera versión de un poema. Para el poeta, la línea más corta entre dos puntos no es la línea recta:

Me gusta andarme por las ramas, No hay mejor camino para llegar a la punta del árbol ... me da náuseas la línea recta; prefiero el buscapiés y su febril zig-zag enflorado en luces ... i. Al diablo con las ornamentaciones exiguas y. las normas de severidad con que las academias ponen el esplendor del mundo! ${ }^{6}$

Estos renglones pueden ser leídos como una defensa de su estilo. Pero pueden considerarse también como una declaración más de su proceso poético, tan rico y sorprendente que muchos de sus versos, como lo vio un crítico, son verdaderos poemas de gran concentración, que pasan como ráfagas ante nuestros ojos, con una vibración que perdura por largo tiempo en nuestra memoria:

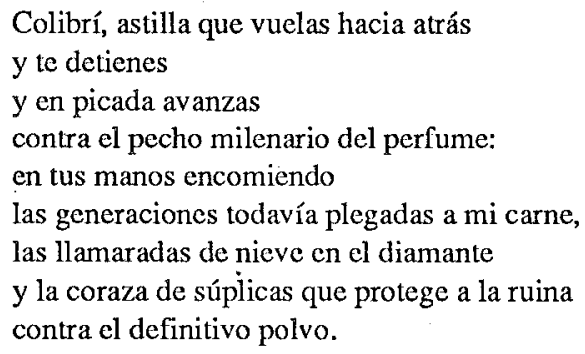

Los anteriores versos forman parte del poema "Contrapunto de la fe", que pertenece a la primera producción del poeta, cuando éste apenas contaba con algo más de veinte años. Lo que hemos transcrito no es la versión original, sino la nueva disposición que le dio el pocta en 1971 y que no ha sido alterada en la edición provisionalmente definitiva de Pedir el fuego (1987); no debemos perder de vista

${ }^{6}$ Marco Antonio Montes de Oca. Las fuentes legendarias (México: Joaquín Mortiz, 1966). Cita tomada de Poesía reunida. 
que en su esencia los poemas ya poseían la tensión y la energía que ha caracterizado la obra de Montes de Oca. La destreza que se adquiere como consecuencia de una entrega total a la actividad de escribir poesía incesantemente, cuando a esta actividad la preside el talento, se manifiesta en la madurez de su expresión. Es interesante observar cómo, al tener el poeta la oportunidad de reeditar un poema, en éste queda impresa la huella de una mayor conciencia en el manejo del lenguaje yel verso, sometido a mayor rigor. Veamos sólo dos ejemplos: "Ruina de la infame Babilonia", el poema con el que hizo acto de presencia por primera vez en la poesía mexicana, tuvo este comienzo en 1953:

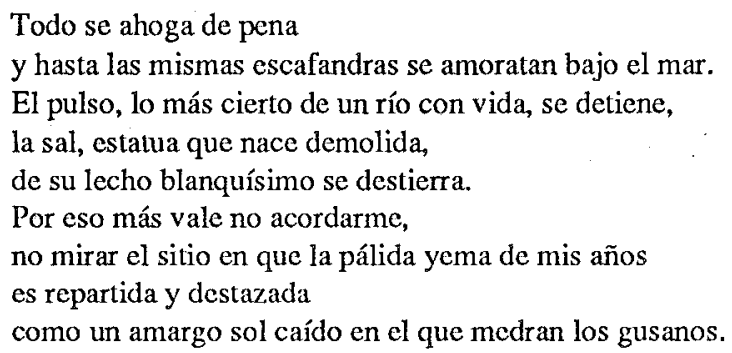

Lo que se busca expresar es el malestar de un estado de ánimo que lo abarca todo. En el sistema poético de Montes de Oca, no basta decir que nos ahoga la pena, sino de qué intensidad es esa pena; si las escafandras evitan perecer bajo el agua, el que se amoraten nos remite a una intensidad. Imagen insólita, que es la naturaleza misma de la poesía que nos ocupa. Esas imágenes insólitas no son la segunda piel del poema sino su verdadero cuerpo. Las asociaciones que establece el poeta describen un trayecto que dan un peso más sólido a la textura de sus poemas. La naturaleza del pulso es su movimiento, es la manifestación de un río con vida que es el hombre; la característica de la sal es su blancura, y con su calidad de polvo es una estatua informe. Pero si el río se detiene y la estatua pierde su blancura, lo que forma la parte más sustancial del yo poético será un amargo sol, sol que trasmuta en potencia negativa que devoraran los gusanos.

En la versión de 1987 el poema ha quedado así:

Todo se ahoga de pena $\mathrm{y}$ hasta las mismas escafandras se amoratan bajo el mar.

El pulso, lo más cierto de un río con vida, y la sal, estatua que nace demolida, ya no reverberan: 
un tajo súbito hiere esta latitud pasmada, dispersa con su sombra piedras de mi esqueleto jamás soldadas.

Lo primero que se nos impone preguntarnos es si se trata de un mismo poema. La respuesta sería sí y no. Sí, porque en el fondo ambos, en un mismo nivel, expresan lo mismo: en los dos casos se habla de una desintegración. Pero en otro nivel, en el del lenguaje, hay algunos cambios que nos dicen que se trata de otro poema al modificarse la estructura de los versos y su misma composición. Se suprimen palabras y se gana en precișión, se ajustan los versos. Pulso y sal tienen una misma cualidad que han perdido. Y la desintegración queda mejor expresada al referirse a una latitud pasmada; ese asombro será borrado por un tajo que, con su sola sombra en su trayectoria, bastará para resaltar la fragilidad del ser.

Podríamos añadir muchos ejemplos. Sería fácil encontrarlos en las 805 páginas que componen la poesía completa de Montes de Oca. Su energía creativa parece ilimitada. La mejor idea que podemos dar de nuestra lectura de este libro es decir que, al avanzar por sus páginas, navegamos a través de un inmenso mar poético de superficie ora apacible, ora embravecido, poemas en los que podemos incursionar sin mayores sobresaltos:
conservo un puente de tablas cruzado por dioses lluviosos, un territorio ambiguo donde el cántaro es aún piedra vacía

y a ratos, travesía por regiones de inestabilidad atmosférica que exigen de nosotros toda nuestra habilidad de lectores para cruzarlas sin zozobra:
En la aguja de piedra
grandes, pararrayos apaciguan el centello del albatros
y se asoma el infierno por la ventana de un lago,
mientras ahuyento al ave carnicera
que quiere por nido el hondón de mi clavícula.

El poema va creciendo imperceptiblemente y nos arrebata como una turbonada; sus partes son derivaciones de una metáfora, que va provocando dentro de su misma lógica un conjunto de asociaciones que hacen posible la apertura del poema hacia varios horizontes semánticos. 
Hablemos otra vez de apariencias. A primera vista, podría parecer que, de principio a fin, Montes de Oca es el mismo. Pero, a medida que avanzamos en la lectura del libro, advertimos que se manifiestan varias búsquedas y varios niveles dentro de las posibilidades mismas del lenguaje. Entre esas búsquedas está la condensación de una nueva síntesis que permita al poema potenciar su expresión. No se busca ya solamente derivar imágenes a partir de un verso seminal, sino establecer una mayor concreción en el verso. Queda, así, una poesía sometida a una mayor tensión, que afirma su verdad. Este resultado es fruto de un proceso en el que se postula un principio que rige, como un eje, todo el acto creativo: pensar en términos estrictamente poéticos, pero sin perder la cualidad sensible de las palabras; esto aparta a Montes de Oca de aquellos poetas que a partir de la poesía producen la poesía, pero con un tal rigor, y tan despojados de emoción, que desembocan en el concepto. Esa cualidad sensible, ese gozo de las palabras y las metáforas, esa instauración del reino de los sentidos, es lo que hace singular la poesía de Montes de Oca, dentro de un dominio que tiene a la poesía como único referente. Por eso, cuando el poeta orienta su expresión hacia una poesía que postula al signo como la única posibilidad de recobrar el verdadero sentido de la palabra, su poesía no se inscribe dentro de lo que se conoce como poesía concreta. La suya más bien recupera una tradición: la del caligrama, en que la escritura, a pesar de privilegiar al significante, jamás pierde de vista al significado. Montes de Oca en esos momentos está más cerca de Tablada que de los poetas concretos brasileños. El lenguaje no puede ser ni puro ni transparente. Si una palabra sólo tiene una posibilidad, si lo que se quiere decir es sólo eso que se quiere decir, la poesía no es posible. La poesía no puede ser como ese vidrio transparente a través del cual podemos ver con nitidez lo que está detrás de él. No, la poesía es como un vidrio opaco, sucio, manchado, que sólo permite ver formas ambiguas; toca al. poeta inventar sentido a esa nebulosa de formas. Y Montes de Oca es el mejor ejemplo de ello.

Unas palabras más para concluir este breve comentario de la poesía de Montes de Oca. Si bien el elogio a la naturaleza está en el centro de su poesía y a ella se incorporan los temas eternos de ésta, el amor, la muerte, el paso del tiempo, etc., pocos han destacado que la poesía de Montes de Oca, su poesía de amorosa raiz, figura entre una de las más bellas que se han escrito en la poesía mexicana de todos los tiempos. Alabanza y tributo a la mujer, Montes de Oca ha escrito un canto perdurable, que no se pierde en las arenas movedizas que con frecuencia pisa el poeta:

Un dios no soy pero te amo

Somos dos ríos más allá de lo explorado 
Nuestra religión es el aire

Quienquiera que nos vea

Después de un minuto no sabría cómo se llama

Hay escándalo y polvo

Un poco de tristeza

En los dos puntos donde termina o nace tu sonrisa

En ese inmenso mar poético nos guía la brújula de nuestra pasión por esta poesía que no revela su misterio en su primer asedio. Este ha sido apenas un torpe acercamiento. 
